\title{
PLANEJAMENTO URBANO EM CURITIBA: SABER TÉCNICO, CLASSIFICAÇÃO DOS CITADINOS E PARTILHA DA CIDADE ${ }^{1}$
}

\author{
Nelson Rosário de Souza \\ Universidade Federal do Paraná
}

\begin{abstract}
RESUMO
O presente trabalho investiga o Plano Preliminar de Urbanismo (PPU) instituido em 1965, matriz do Plano Diretor que transformou o espaço urbano de Curitiba na década de 70. A análise focaliza o discurso técnico e seu procedimento de classificação do espaço e da população da cidade. O saber técnico articulou-se fortemente às estratégias de divisão desigual do espaço e orientação diferenciada das políticas urbanas. Essa articulação pode ser constatada ao analisarmos a argumentação técnica mobilizada no PPU para definir a localização dos eixos estruturais, cujo efeito foi atribuir um valor suplementar a espaços já valorizados e formar um estoque para expansão seletiva do centro da cidade.
\end{abstract}

PALAVRAS-CHAVE: Curitiba; urbanismo; política urbana; planejamento urbano; saber e poder; discurso.

\section{INTRODUÇÃO}

Curitiba é a capital do estado do Paraná e conta com aproximadamente 1500000 habitantes. É uma cidade acostumada aos movimentos de expansão populacional. Depois de um fluxo migratório de europeus no final do século XIX e início do século $\mathrm{XX}$, a cidade vem recebendo, desde a década de 1950, um grande número de migrantes vindos do interior do Paraná e de outras regiões do Brasil, resultado da industrialização urbana e da modernização agrícola. Ainda hoje Curitiba segue um ritmo de crescimento populacional alto. O crescimento da capital paranaense combina-se, agora, com um vertiginoso avanço demográfico dos municípios que lhe fazem fronteira (ULTRAMARI \& MOURA, 1994; KLEINLE et al., 2000). Ao que tudo indica, tratase de um crescimento paralelo e articulado entre núcleo urbano e região metropolitana. A capital

\footnotetext{
1 Artigo originalmente apresentado na sessão "Investimento público e produção do espaço” durante o Simpósio Cidade e poder, realizado entre 23 e 24 de abril de 2001 na Universidade Federal do Paraná, promovido pela Revista de Sociologia e Política e pelo Grupo de Estudos Cidade, Poder e Sociedade. A realização deste trabalho contou com o apoio da Pró-Reitoria de Pesquisa e Pós-Graduação da UFPR.
}

parece selecionar seus migrantes, reservando a Região Metropolitana de Curitiba (RMC) como espaço para as classes populares, enquanto privilegia o recebimento das camadas médias e altas dos novos migrantes. Essa seleção não natural de fluxos migratórios tem, conforme será explicitado neste artigo, seu ponto de partida nas transformações urbanas planejadas e experimentadas pela cidade na década de 70, quando foram executadas as principais diretrizes do Plano Preliminar de Urbanismo (PPU) ${ }^{2}$.

A modernização urbana de Curitiba se fez num contexto nacional de ascensão das forças burocrático-militares e de fortalecimento da ideologia do planejamento racional e, especialmente, da crença no poder da Arquitetura e do Urbanismo no ordenamento do espaço e na (trans)formação do comportamento das camadas mais pobres da população.

O presente estudo propõe analisar os procedimentos e instrumentos do urbanismo curiti-

\footnotetext{
2 Plano elaborado em 1965 pela empresa Serete associada ao escritório do urbanista Jorge Wilheim, ambos de São Paulo. Este plano, com poucas modificações, virou Plano Diretor (PD) e foi executado pelo IPPUC.
} 
bano $^{3}$ e como ele foi construído como empreendimento discursivo estratégico para a divisão do espaço da cidade e para a codificação dos novos fluxos populacionais, suas experiências e relações. A pergunta que orienta este artigo é: quais categorias de análise e intervenção o urbanismo curitibano mobilizou e como elas operaram estrategicamente no desenho do perfil da população e na distribuição e valorização dos espaços da cidade? Ou seja, qual o significado político da ação discursiva e das intervenções a ela articuladas? Enfim, por que certas "verdades" urbanas foram construídas?

Para responder às questões acima elaboradas, o foco recairá sobre o PPU, especialmente na sua argumentação "técnica" a respeito da localização dos eixos estruturais e a propósito da sua importância para a cidade e seus habitantes. O PPU é rico em detalhes quanto à decisão sobre onde desenhar os eixos. Argumentos sobre a organicidade do todo urbano são agrupados lado a lado a diagnósticos sobre a população curitibana e a vocação da cidade. Nas fendas do discurso técnico emerge com vigor o conteúdo político das decisões tomadas.

\section{A REFERÊNCIA MODERNISTA}

Não é difícil perceber a forte influência de alguns princípios do urbanismo modernista no planejamento urbano de Curitiba. A divisão da cidade em zonas funcionais excludentes, a transformação de ruas em avenidas, a hierarquização do sistema viário, a construção da cidade como todo orgânico a ser equilibrado e a conseqüente classificação da população segundo "necessidades" identificadas pela razão técnica inspirada num conceito de homem universal, são procedimentos típicos do urbanismo modernista adotados pelos planejadores da capital paranaense. Também é característico do traço modernista a aposta no planejamento global como empreendimento capaz de superar as contradições sociais a partir tão-somente da redefinição do espaço.

É duplamente interessante analisar o urbanismo modernista praticado em Curitiba nos anos $60 \mathrm{e}$

\footnotetext{
3 O uso desta designação não objetiva sugerir a existência de uma escola de urbanismo ou de um modelo de ação urbana típicos de Curitiba. "Urbanismo curitibano", neste caso, designa apenas o conjunto de intervenções planejadas que Curitiba vem experimentando há trinta anos, elaboradas e executadas pelo mesmo grupo de urbanistas.
}

70 do século passado. Primeiro porque hoje o poder público municipal, ainda sob o comando dos protagonistas das reformas urbanas idealizadas naquele período, fez aprovar uma nova lei de zoneamento que redefine as prioridades dadas inicialmente aos eixos estruturais e de quebra ressignifica a rodovia BR-116 ${ }^{4}$ em seu trecho que atravessa a cidade. $O$ interesse se completa quando percebemos que no campo do urbanismo estamos vivendo, depois de um declínio do urbanismo de plano, uma revalorização do "planejamento estratégico" com vistas a produção de uma "imagem da cidade" vendável no mercado globalizado (ARANTES, 2000; SÁNCHEZ, 2001). Investigar o discurso técnico articulado às grandes intervenções urbanas da Curitiba dos anos 1970 pode contribuir para as análises sobre as rupturas, continuidades e reviravoltas das recentes políticas urbanas implementadas na cidade.

Ainda que o urbanismo modernista tenha se caracterizado inicialmente como um movimento de vanguarda na luta pela retomada do espaço urbano pelo poder público contra o caos gerado pelo mercado nas grandes cidades, é sabido que os fundamentos desse tipo de planejamento e as práticas a ele associadas são contraditórios. É notório que as vanguardas urbanistas foram facilmente assimiladas pelo capitalismo e institucionalizadas. O debate atual apenas questiona se este foi um mal de origem ou um desvio de percurso (ARANTES, 1998). O urbanismo de plano foi, para dizer pouco, absorvido pelas forças produtivas vigentes. $\mathrm{O}$ impulso inicial de denúncia do caos provocado pela máquina, presente, por exemplo, em Le Corbusier, resultou no seu avesso: uma defesa da configuração funcional maquinista do espaço urbano. Os problemas típicos da cidade industrial foram deslocados e não ultrapassados pelas intervenções urbanas modernistas.

Ao eleger a racionalidade técnica urbanística como único instrumento capaz de superar as contradições capitalistas, inclusive a divisão da sociedade em classes, o urbanismo modernista revelou-se utópico. A utopia de gerar uma igualdade social a partir do planejamento urbano, sem a

\footnotetext{
4 À época do PPU a BR-116 era denominada BR-2. Para maior clareza faremos referência à rodovia apenas como BR-116. Nos mapas do PPU (reproduzidos neste artigo) a BR-116 está representada por uma linha escura e transversal à cidade no sentido nordeste-sul.
} 
necessidade de transformar o modo de produção, ou sequer mexer no regime da propriedade privada, dinamizou, em muitos casos, uma engrenagem autoritária. No contexto de valorização da racionalidade técnica o agente urbanista apareceu como autoridade acima dos conflitos e da sociedade política, uma vez que se apresentou como portador da verdade única sobre a cidade e seus habitantes.

A perspectiva adotada neste artigo visualiza a cidade como espaço de conflito, onde, a busca da "verdade" urbana, ainda que se revista de uma aparente neutralidade técnica, é procedimento de poder. A história do Urbanismo aponta a estreita relação entre a delimitação do objeto dessa disciplina, a construção científica dos problemas urbanos e a preocupação dos reformadores sociais em ordenar o caos, normalizar os comportamentos das classes populares, enfim, constituir trabalhadores sedentários, disciplinados, comprometidos com o processo produtivo e com o mercado. A articulação entre reforma urbana e questão social significou, antes de mais nada, uma nova página nas relações de força, pois disseminou no espaço da cidade o poder normativo (TOPALOV, 1996).

A crítica ao urbanismo modernista exige a inversão do seu percurso. Tal procedimento permite perceber que o indivíduo e suas necessidades não são pré-existentes ao olhar técnico. Os urbanistas, influenciados pelo liberalismo, é que incorporam esta leitura. O sujeito de necessidades é uma construção da economia política, fundamental para a sociedade de consumo (FOURQUET, 1973). Baudrillard, numa análise crítica, procura dissolver os vínculos arbitrários e naturalizados do tipo: "o lazer é uma função da necessidade de lazer". Em resumo ele diz: "[...] o homem não está postado num ponto de partida, com suas necessidades e condenado pela Natureza a se completar enquanto Homem" (BAUDRILLARD, 1969, p. 67). Para ele essa proposição define uma "função indivíduo" e cria o mito funcional que anima o consumo e, porque não dizer, o urbanismo modernista. Dreyfus, abordando o mesmo tema, vai além e afirma que o urbanismo, a partir das idéias de necessidade e função, tende a construir um espaço para uma "civilização de consumidores" (DREYFUS, 1976, p. 40). Não é ingênuo o procedimento de classificar a população segundo suas necessidades e em relação às necessidades naturais da cidade, ambas tomadas como objetos pré-dados. Trata-se de uma prática cujo fim é determinar o tipo de equipamento, sua função e localização no espaço urbano segundo as "necessidades" dos diferentes habitantes construídas a partir do olhar "tecnocêntrico" do urbanista.

Equipamentos urbanos planejados devem ser entendidos como equipamentos de poder, pois atuam dividindo certos espaços, integrando, combinando ou bloqueando outros, reforçando as hierarquias sociais e normalizando comportamentos. Os equipamentos distribuídos na cidade, a partir de estudos técnicos rigorosos, codificam os fluxos, regulam as exclusões, ou inclusões parciais, dos diferentes habitantes urbanos diante dos múltiplos espaços. Os lugares urbanos adquirem significados renovados pela determinação prévia das suas formas e usos gerada na e pela intervenção técnica. Da perspectiva do urbanismo modernista, dar sentido aos espaços é tarefa fortemente articulada à classificação dos usuários segundo o perfil e a necessidade de cada grupo. O desenho em relevo das "carências" coletivas se faz sobre o fundo idealizado de um urbano totalizado e em movimento evolutivo. Os equipamentos urbanos cuidadosamente planejados e distribuídos na cidade expressam, e ao mesmo tempo atuam sobre, o jogo de forças pela apropriação dos bens urbanos de ordem material e simbólica, ainda que apresentem uma aparência de simples instrumentos funcionais da vida na cidade.

No momento da irrupção dos equipamentos urbanos, não se encontra uma função e sim um embate de forças. É preciso ter clara essa afirmação, pois o discurso do planejamento urbano costuma inverter os elementos e acaba tomando a função (efeito) pela origem e, como conseqüência, pela explicação. Partindo-se das funções que o urbanismo modernista associa à cidade: habitar, trabalhar, circular, recrear, educar, praticar esportes, usufruir a natureza, é comum tomar os equipamentos coletivos (sistemas viários e de transporte, escolas, parques, hospitais, praças) por máquinas que concretizariam as "necessidades" associadas àquelas funções. $\mathrm{O}$ urbanismo daria "forma" a uma cidade orgânica, ou a uma totalidade mecânica, maquinal. Ou seja, o funcionamento equilibrado do todo urbano daria vazão às demandas inscritas na ordem social e em cada uma das suas partes. No centro das funções estaria o sujeito humano que daria fundamento a essa racionalização (FOURQUET, 1973). O vetor do urbanismo é esse sujeito de necessidades naturais que precisariam ser preenchidas pelo consumo: 
de linhas de circulação, de espaço verde, de tempo livre etc. ${ }^{5}$

Da ótica do urbanismo modernista, a satisfação funcional das necessidades pelo bom ordenamento urbano é que geraria a igualdade, não como resultado do conflito político ou bélico, mas como efeito da racionalidade planejadora.

Ocorre que o urbanismo modernista, ao eleger a razão técnica como único critério válido para o ordenamento do espaço urbano, critério externo e acima da luta política, bloqueia a possibilidade de uma sociabilidade marcada pela autonomia e pelo livre jogo de forças no espaço público. Ao construir a cidade como todo orgânico ou maquinal e as necessidades como dados naturais o urbanismo modernista nega autonomia ao diferente na justa medida em que o coloca numa posição hierarquicamente inferior e dependente da integração ao modelo de igualdade, qual seja: o urbano funcional. A grade funcionalista, típica do urbanismo modernista, impede o conflito a partir do diferente, caçando-lhe a palavra ao constitui-lo como resíduo. O urbanismo inscreve-se na vontade de racionalidade e poder autoinstituindo-se como a "ordem em si" elevada à classe de necessidade. O sucesso desta operação coloca o saber técnico como fonte legítima e exclusiva da solução dos conflitos e o urbanista como juiz incontestável da nova ordem. Nesse jogo a técnica aparece apenas como meio que viabilizaria a realização das necessidades e da felicidade numa sociedade perfeita porque de espaço racionalmente planejado. Concretamente, a construção da cidade como todo orgânico coloca em marcha a engrenagem que combina saberes e práticas promovendo a legitimidade de uma partilha urbana desigual e a normalização do comportamento de sujeitos sujeitados ${ }^{6}$. Os procedimentos do urbanismo modernista bloqueiam a

\footnotetext{
5 Foucault fez uma interessante análise do desbloqueio da "arte de governar", ou, da articulação entre soberania, disciplina e gestão governamental a partir da emergência dos "problemas de população" e da própria população como "sujeito de necessidades" (FOUCAULT, 1979, cap. XVII).

6 Dado os limites deste artigo a análise aqui apresentada enfatizará a relação do discurso técnico urbanista com a partilha desigual do espaço. Para um estudo sobre urbanismo e normalização do comportamento em Curitiba, ver Souza (1999). Análises históricas e teóricas do tema urbanismo e normalização podem ser encontradas em Topalov (1996), Dreyfus (1976) e Fourquet (1973).
}

possibilidade do cidadão tomar parte na construção da sociedade. O máximo de participação da sociedade, que o saber técnico modernista costuma admitir, está em referendar as decisões tomadas a partir de critérios "racionais" indiscutíveis.

Dizer que o planejamento urbano em Curitiba sofreu influência do urbanismo modernista não significa apostar numa incorporação perfeita do segundo pelo primeiro. Parece mais prudente e coerente pensar em termos de uma inspiração que conduz a adaptações de categorias e procedimentos, cujos efeitos precisam ser cuidadosamente avaliados, pois estão estreitamente associados às configurações próprias do momento, do lugar, das forças e dos agentes envolvidos. Sendo assim, a análise da concepção dos eixos estruturais espera explicitar a construção de uma partilha desigual do espaço urbano em Curitiba e os mecanismos da sua reprodução. $\mathrm{O}$ estudo contribui também para percepção das adaptações e transferências empreendidas pelos urbanistas brasileiros a partir da matriz modernista e diante das experiências e configurações de poder locais.

Vejamos então como o urbanismo de plano, no caso de Curitiba, articulou estrategicamente a construção dos problemas e necessidades da "população" (classificada, caso a caso, a partir do que tinha de "igual" ou "diferente" em relação ao modelo de cidade orgânica) com a partilha desigual do espaço e a idéia de "bom" funcionamento e desenvolvimento urbano.

\section{A CLASSIFICAÇÃO ESTRATÉGICA DO ESPAÇO E DA POPULAÇÃO}

O PPU foi um plano global cujo objetivo era uma total reordenação da cidade capaz de modernizá-la e prepará-la para o desenvolvimento econômico. Do conjunto dos seus procedimentos destacaremos a construção discursiva a propósito dos chamados "eixos estruturais lineares" e sua localização. Os eixos estruturais foram concebidos e posteriormente implantados como linhas que combinariam o tripé integrado: sistema viário, transporte de massa e uso do solo, de modo a viabilizar, segundo os urbanistas, o desenvolvimento ordenado da cidade (ver foto abaixo). Esses eixos são dois: o nordeste-sudoeste foi implantado primeiro, é o mais longo; o leste-oeste era, na sua origem, mais curto, sofria uma interrupção quando encontrava a BR-116 (ambos estão destacados em cinza claro no Mapa 1, "Proposta de esquema viário" do PPU, reproduzido a seguir). 
Fotografia 1: Vista do sistema de transporte trinário - sentido nordeste.

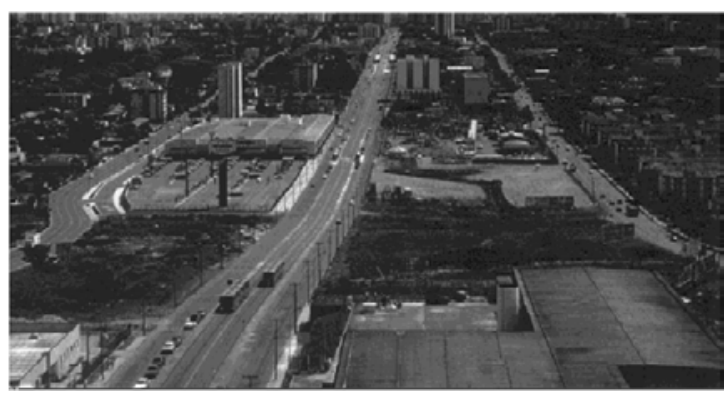

Mapa 1 - Proposta de esquema viário - PPU

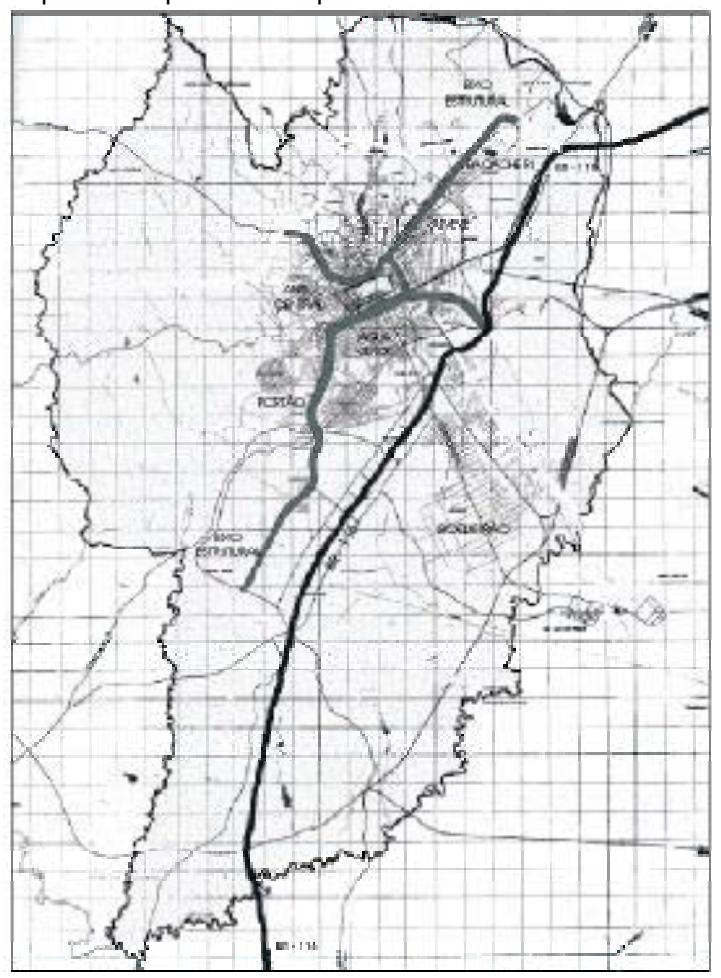

O PPU é um documento representativo da racionalidade urbanística e da relação entre planejamento do espaço e governo da população em Curitiba. Planejar, aos olhos dos técnicos do PPU, significava diagnosticar as necessidades e disfunções da cidade e de sua população a partir de uma razão orientada para construção de uma espaço universal para um homem abstrato. Tal empreendimento solicitou pensar a cidade como todo orgânico e sua população como sujeito capaz, ou não, de operar o bom funcionamento do corpo urbano.

Na suas primeiras páginas o PPU busca traçar um perfil positivo do seu objeto: a população urbana de Curitiba. $\mathrm{O}$ estudo afirma que a origem da maioria dos seus migrantes é o sul do Brasil (europeu e rico). A base de dados é o cadastro do TRE (segundo o PPU as informações do IBGE não seriam confiáveis), o que significa que analfabetos, não-eleitores e re-imigrados, ou seja, os pobres, estavam excluídos desta representação. O próprio texto do PPU reconhece os limites da amostra, mas ameniza o problema, com argumentos interessantes: "[...] o eleitor tende a ser das camadas sociais mais altas, e assim deixando de ser representada a população de camadas mais baixas. Isto em parte é contrabalançado pelo alto índice de alfabetização dos habitantes da Região Sul do país, e que constituem a maior parte dos imigrantes" (PMC,1965, p. 12).

A argumentação desencadeia um ciclo vicioso: os pobres (na maioria analfabetos) podem não estar representados nos dados, mas os mesmos dados "revelariam" que a maioria vem do sul onde o analfabetismo seria baixo, o que validaria os dados. Bem, se os dados do IBGE não são confiáveis e se os números do TRE não incluem pobres, analfabetos e re-emigrados, como afirmar que os imigrantes do sul são a maioria? E, principalmente, por quê? A idéia de maioria aqui é fundamental, pois permite classificar pobres, analfabetos, negros, nordesti-nos - enfim, "outros" - como minoria não relevante para o planejamento dos investimentos urbanos.

O principal objetivo do PPU era dotar racionalmente a cidade dos atributos técnicos e espaciais necessários ao progresso econômico. Para tanto, o olhar urbanista construiu as dificuldades como "residuais", momentâneas e recentes, em oposição ao duradouro, essencial e natural, capaz de indicar as potencialidades de Curitiba. A população pobre, habitante de uma região insalubre, foi representada como insignificante em termos estatísticos e tornou-se invisível para o planejamento.

No jogo de classificação do espaço e da população para determinar o potencial da cidade os técnicos construíram uma história da cidade na qual aparece em primeiro plano a população de origem européia e o processo da sua integração social, econômica e espacial. Essa história apontaria a direção "saudável" do crescimento urbano (o sentido longitudinal sudoeste-nordeste) e confirmaria os espaços passíveis de investimento. Os imigrantes pobres e recém-chegados são apresentados como minoria que precisa 
adaptar-se ao meio urbano civilizado e cujo espaço é problemático.

A ocupação urbana empreendida pelos migrantes europeus teria sido saudável, pois teria propiciado, segundo o PPU, "um desenvolvimento relativamente contínuo, centrífugo e homogêneo" (PMC, 1965, p. 81); e teria, ainda, limitado a "especulação terrenista", o "parcelamento em lotes" e os loteamentos clandestinos, resultado de uma recente "migração de nacionais". Uma ocupação urbana racional por uma população saudável teria feito de Curitiba, até pouco tempo, uma cidade orgânica. $\mathrm{O}$ planejamento deveria pautar-se pela recuperação dessa condição de equilíbrio propiciada pelos colonizadores portugueses e imigrantes estrangeiros.

É interessante perceber, aqui, o procedimento de construção do perfil da população em relação ao espaço a ser valorizado. Após relacionar o tipo de população à forma de ocupar o solo e ao caráter orgânico da cidade, o texto do PPU informa que o desequilíbrio de Curitiba começou após a Segunda Guerra, com as transformações econômicas do país e "[...] uma certa imigração, especialmente de nacionais [...]. Comparece então, com muito maior vigor o mecanismo do loteamento [...], sem controle do poder público. Tal fenômeno ocorreu especialmente no setor sul, mais plano de menor valor comercial, em virtude das freqüentes inundações da baixada [...]. Em decorrência desta atividade comercial indisciplinada, a ocupação do solo deu-se parcialmente em terrenos de difícil drenagem e de serviços públicos onerosos" (PMC, 1965, p. 81; grifos do autor).

Uma determinada conjuntura teria levado, então, ao aparecimento do "outro". Segundo os urbanistas do PPU, a "migração de nacionais", suas demandas combinadas com descontrole - leia-se, falta de planejamento racional por parte da administração municipal - teria sido responsável pela ocupação indisciplinada do sul da cidade (para além da BR-116, especialmente do bairro do Boqueirão) ${ }^{7}$. Ainda que alguns vazios urbanos

7 O Boqueirão é um bairro de Curitiba localizado ao sul da rodovia BR-116, ver Mapa 1, "Proposta de esquema viário - PPU”, acima. Quando da confecção do PPU ele ainda não estava subdividido. Trata-se de um bairro ocupado principalmente nos anos 50 e 60, sendo uma região alagadiça, os preços baixos dos lotes atraíram os imigrantes de baixa renda. tivessem sido preenchidos colaborando com o desenvolvimento orgânico da cidade (pois propiciaram a ligação do centro com os espaços ocupados pelos imigrantes europeus), a ocupação descontrolada e exagerada em outros espaços, nitidamente pelos imigrantes nacionais, teria gerado desvios inorgânicos. É nítida a inversão hierárquica promovida pelo PPU, a especulação imobiliária na periferia aparece como mais importante na conformação do espaço urbano do que aquela presente nos terrenos mais valorizados e centrais. As ocupações urbanas "desordenadas" em regiões de baixo custo imobiliário emergem no discurso técnico como causa e não como efeito dos desequilíbrios da cidade. De todo modo, o texto do PPU é contraditório ao apontar a gravidade dos problemas gerados pela ocupação da região ao sul da BR-116 e, ao mesmo tempo, classificar esse fenômeno como insignificante em relação ao todo urbano. $\mathrm{O}$ discurso técnico funciona estrategicamente como instrumento no jogo de forças urbano ao anunciar tensões como essas sem as enfrentar.

Os técnicos que analisaram a situação do bairro do Boqueirão pouco estavam interessados na solução dos problemas que a população ali instalada vivenciava ${ }^{8}$. Se para os "migrantes nacionais" a ocupação do bairro foi a solução encontrada no enfrentamento da competição desigual no meio urbano, para o olhar técnico tal ocupação era o problema. Aos urbanistas coube recomendar um não investimento naquele local e indicar quais áreas deveriam ser valorizadas por suas qualidades "naturais", "históricas" e, principalmente, por motivos técnicos. Ou seja, foi fundamental para o projeto de reforma urbana a construção discursiva de um lugar como o avesso, ou o negativo, do espaço planejado e capaz de legitimá-lo por meio de contraste. Em meados da década de 60, quando da elaboração do PPU, o Boqueirão foi constituído como oposto da ordem racional planejada e, ao mesmo tempo, natural.

8 Esse procedimento perpetuou-se na administração do município pelos urbanistas. Não por acaso as associações de moradores, ao oporem-se ao projeto de desfavelamento apresentado pelo Prefeito Jaime Lerner em 1980, questionaram a recusa da administração municipal em utilizar recursos técnicos para tornar salubres espaços considerados "insalubres" pelos urbanistas e ocupados por favelas (OS BAIRROS DEVERIAM, 1980). 
Os técnicos esforçaram-se, então, para distinguir o que era saudável do que era prejudicial ao futuro da cidade, e os critérios de avaliação foram expostos no PPU: "Se compararmos qualquer prancha gráfica de serviço público com a localização de edificações e de loteamentos, perceber-se-á terem as redes permanecido a grosso modo na direção sudoeste-nordeste, enquanto os loteamentos levaram os limites da zona urbana abranger vastas glebas ao sul, a sudeste e a leste do setor urbano contínuo. Desejaríamos insistir no caráter inorgânico desta ampliação de Curitiba" (PMC, 1965, p. 81-82; grifos do autor).

A restrição dos serviços públicos a certos espaços não é apresentada, é claro, como sinal de discriminação, mas como evidência de que o natural, o saudável, é o investimento em direção às regiões sudoeste e nordeste e em suas populações. O contínuo é sinônimo de orgânico. A dispersão aparece como dado inorgânico e residual, ainda que em "expansão exagerada", pois teria sido gerada pela indisciplina administrativa e pelo perfil negativo da população.

A lógica do plano leva a mútua determinação entre espaço e população, pois a valorização do "lugar" pelos investimentos públicos está associada à classificação dos seus usuários concretos ou potenciais. A realização do valor nas áreas investidas pelo planejamento depende também do controle daqueles que podem atuar para sua desvalorização.

\section{A DENSIDADE COMO CATEGORIA-CHAVE}

Segundo o PPU Curitiba teve sua ocupação urbana marcada pela "dispersão" e pela "tendência longitudinal" em relação à BR-116 (linha sudoestenordeste). Esses dois aspectos adquirem uma grande importância ao longo do PPU e formam a base das proposições e da execução do plano. A dinâmica do plano, a sua lógica, dá-se pela polarização dos dois elementos acima citados. A "tendência longitudinal" aparece como pólo positivo, elemento a ser valorizado, é celebrada pelos técnicos da administração municipal como "vocação", como evolução "natural" e ao mesmo tempo racional. A "tendência longitudinal" surge como o lado de dentro. Por outro lado, a "ocupação extensiva" (a dispersão da população) será apreendida como pólo negativo, algo a ser corrigido e ordenado, o lado de fora.

Associada à polarização acima indicada aparece a concepção de densidade. No PPU a densidade é entendida como meio capaz de viabilizar o planejamento urbano quando alta e inviabilizá-lo quando baixa. A adequação da densidade é o fim a ser alcançado pelo próprio planejamento. A ação racional corrigiria a densidade baixa e geraria o desenvolvimento orgânico da cidade. Só a alta densidade viabilizaria economicamente os investimentos públicos em infra-estrutura e serviços. Caracterizar as áreas de dispersão será uma das tarefas dos urbanistas. Bairros como o Boqueirão, pela intensidade da sua dispersão, pelo perfil dos seus habitantes, pela ocupação recente e pelas características "naturais" do seu terreno, não aparecem como áreas prioritárias para os investimentos da administração, sendo construídos como o lado de fora.

Para auferir o grau de dispersão o PPU lança mão, estrategicamente, do critério da densidade. A área de maior densidade em Curitiba no anos 1960 era a central e suas adjacências, onde se concentravam as habitações da elite. As classes populares estavam dispersas nos bairros. Ao eleger a densidade como critério de escolha para os investimentos públicos, seguindo a tradição modernista de urbanismo, o PPU reafirma a divisão do espaço em duas cidades, ou melhor, entre o que está dentro e fora da fronteira urbana. A segmentação do espaço, nesse caso, é correlata à diferenciação dos seus habitantes e à polarização entre tendência longitudinal e ocupação extensiva. Os técnicos do PPU fizeram um esforço extra de racionalidade, conforme veremos adiante, para tentar comprovar, a partir do critério de densidade, a vocação natural da cidade para o crescimento linear nordestesudoeste.

O pólo positivo (tendência longitudinal), é importante que se diga, precisava do negativo (ocupação extensiva) para viabilizá-1o9 . Ao lado do pólo positivo outros elementos de mesma carga foram sendo aglutinados. A tendência longitudinal estaria de acordo com a vocação da cidade, a rentabilidade, as necessidades, o progresso, a quali-

\footnotetext{
9 Por isto não é de todo correto afirmar que o Boqueirão foi desprezado pelo PPU, como sugere por exemplo o estudo da Fundação Cultural de Curitiba (FCC, 1995). Em rigor, ele foi desprezado enquanto possível alvo de investimentos e valorização e foi lembrado, como vimos, enquanto contraexemplo, sem o qual seria mais difícil convencer sobre a plausibilidade do planejamento.
} 
dade de vida, o caráter orgânico, a preservação da história, da natureza. Enfim, ela jogaria a favor da racionalidade técnica. Do outro lado fez-se o procedimento inverso: junto à ocupação extensiva foram agregados traços negativos: o alto custo, o atraso, o caráter inorgânico, não-natural e irracional.

Tomar a tendência longitudinal como um dado natural significou justamente abstrair a história do Boqueirão e a resistência dos seus moradores que construíram uma infra-estrutura urbana praticamente à revelia da administração municipal. Significou também ignorar a função de barreira que o equipamento estrada tem lado a lado com a função de ligação, ou melhor, o plano incorporou a função de barreira como algo positivo e elaborou a argumentação para que esse obstáculo não fosse transposto pela linearidade do planejamento ${ }^{10}$. A racionalidade técnica construiu, a partir desse procedimento, certos espaços e indivíduos como "apêndices" do corpo saudável da cidade, e o Boqueirão é o exemplo mais acabado dessa obra da razão técnica.

No percurso de construção da tendência longitudinal como vocação da cidade fundada na densidade, o PPU lançou mão da divisão do espaço urbano em unidades de vizinhança (UV). O recurso pretendia medir a densidade nas diferentes áreas de Curitiba. A divisão, que foi enunciada como arbitrária, na verdade teve um vetor, qual seja, a articulação com a classificação dos espaços e seus habitantes. A mensuração da densidade objetivava revelar o desenho inquestionável do progresso da cidade em poucos eixos lineares contra a suposta distorção das múltiplas expansões radiais que

\footnotetext{
10 A idéia de um eixo saindo do centro da cidade e seguindo pela avenida Mal. Floriano Peixoto até o Boqueirão não é original do PPU, foi introduzida no PD depois de muitas críticas de técnicos dissidentes e resistência dos habitantes do bairro que, finalmente, viram sua existência reconhecida. Ainda assim o eixo implantado posteriormente, e que sequer aparece nos mapas do PPU, não é um eixo estrutural e sim uma via coletora, basicamente de transporte coletivo. Neste caso a legislação de uso do solo e a infra-estrutura não são as mesmas que acompanham os eixos estruturais. Ou seja, os investimentos em infra-estrutura, com capacidade de valorizar o solo, foram pequenos, no caso do Boqueirão, ao passo que os investimentos na normalização (leia-se: integração parcial-funcional) dos habitantes foi significativo, entre os quais o próprio eixo de transporte é um exemplo. Sobre esse tema ver Souza (1999).
}

desorganizariam o espaço. O esforço do PPU estava em associar uma imagem de vocação natural de crescimento da cidade, construída no passado, à racionalidade planejada empreendida no presente e com vistas ao futuro. É interessante perceber que a construção da cidade como todo orgânico abre caminho para a representação que combina o "desenvolvimento" natural e racional do espaço e de sua população.

Ocorre que a articulação entre razão e natureza, ou a leitura racional da vocação natural da cidade tem como fundamento a luta pela apropriação e valorização do espaço urbano. A própria divisão das UV não é arbitrária, segue a lógica da naturalização da tendência longitudinal, numa inversão nada ingênua (ver mapa 2 "Densidade demográfica por unidade de vizinhança, 1964 - PPU”, abaixo).

Mapa 2 - Densidade demográfica por unidade de vizinhança, 1964 - PPU

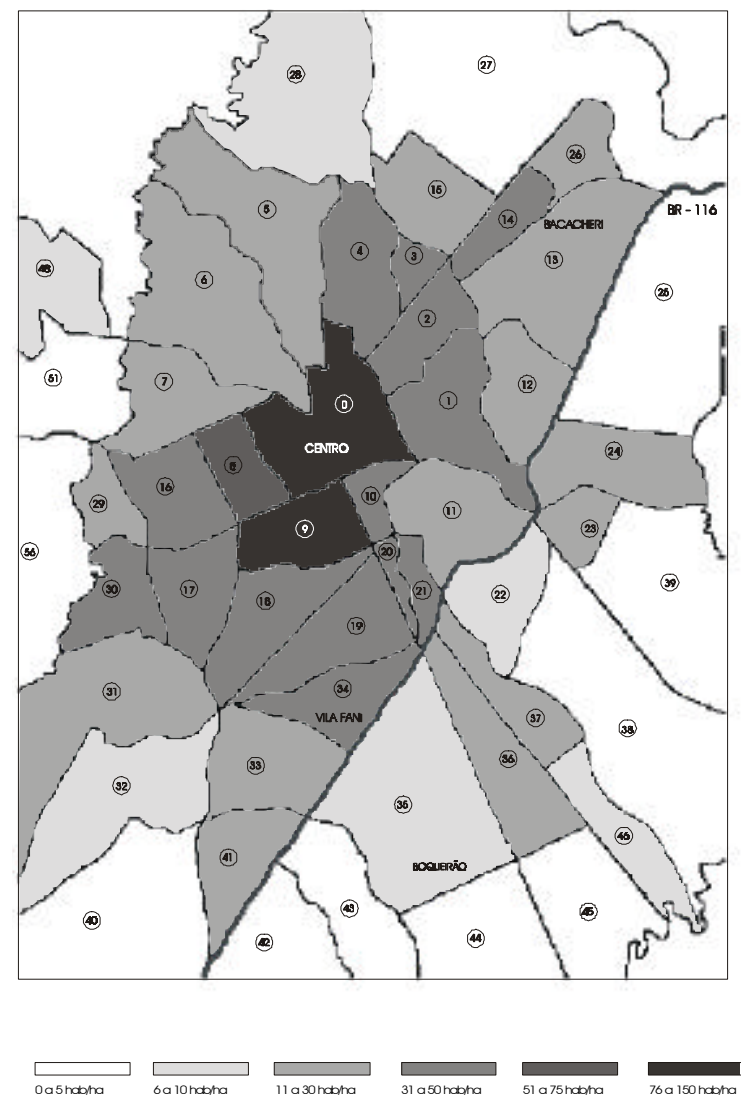

Primeiro a BR-116 é tomada pelos técnicos como limite das unidades de vizinhança do nordeste ao sudoeste. Ainda que seja usual tomar rodovias, linhas de trem ou rios como limites de unidades espaciais, é preciso sublinhar o caráter político 
das abordagens que buscam amparo nesses instrumentos para não exprimir a continuidade de processos que ultrapassam as fronteiras tecnicamente concebidas.

No caso em foco, reafirma-se o princípio de que a estrada deve ser entendida como barreira. O bairro do Boqueirão, por sua vez, foi dividido em poucas e grandes UV. Duas delas são significativas, pois margeiam a rodovia no ponto mais próximo ao centro da cidade. Uma é a UV 36, que se localiza entre a margem direita do Rio Belém ${ }^{11}$ até a Avenida Mal. Floriano Peixoto; outra (a 35) abriga um quartel do exército cuja área não foi subtraída no cálculo da densidade. Ainda na região sul outra UV (a 37) foi demarcada. A separação dessas UV daquelas estabelecidas do outro lado da BR-116 ilude porque minimiza a transposição da estrada pelos habitantes em busca de terrenos mais baratos. A dimensão do recorte impede a avaliação da densidade num desenho perimetral ao centro no sentido sudeste. Como agravante, os dados sobre densidade foram retirados do censo escolar. Significa que na faixa das famílias mais pobres, onde provavelmente muitas crianças estavam fora da escola, a densidade foi subavaliada.

No Mapa 2, "Densidade Demográfica por UV em 1964 - PPU" (acima) é apresentado somente o núcleo central (UVs 0,8 e 9) com densidade superior a $50 \mathrm{hab} / \mathrm{ha}$. A seguir os urbanistas visualizam uma faixa, a nordeste e a sudoeste, com densidade entre 30 e $50 \mathrm{hab} / \mathrm{ha}^{12}$. Ocorre que, seja pela assimilação da rodovia como barreira, seja pela critério utilizado para recortar cada UV, o que poderia ser tomado como faixa perimétrica de crescimento a partir do centro é avaliado como tendência longitudinal sudoeste/nordeste. As UVs $10,16,17,18,19,20,21,30$ e 34 , que praticamente contornavam o centro partindo do oeste e

11 No Mapa 2 "Densidade demográfica por UV em 1964" (acima) o Rio Belém é representado pela linha que, depois de cruzar o centro da cidade, serve de limite entre as UVs 36 e 37, 45 e 46 a partir da BR-116. A avenida Mal. Floriano Peixoto está representada pela linha fronteiriça entre as UVs 35 e 36,44 e 45.

12 A própria divisão das faixas entre "11 a 30 hab/ha" e "31 a $50 \mathrm{hab} / \mathrm{ha"} \mathrm{deixa} \mathrm{muitas} \mathrm{dúvidas} \mathrm{e} \mathrm{apresenta-se} \mathrm{como}$ estratégica. As áreas próximas à rodovia, de um lado e de outro, estariam quanto próximas ao limite de $30 \mathrm{hab} / \mathrm{ha}$ ? Não formariam, neste caso, um todo homogêneo que aparece dividido? indo até a BR-116, são aglutinadas sob o guardachuva de tendência longitudinal sudoeste. E as UVs 1, 2, 3, 4 e 14 são assumidas como tendência longitudinal nordeste. Acontece que a mancha formada por essas UVs poderia ser lida como radial, caso o recorte das mesmas se combinasse com uma subdivisão das UVs 5, 6 e 7 (num novo desenho menos alongado e de menor tamanho), fechando um anel de densidade alta ao redor do centro $^{13}$. A nova mancha radial, não mais "longitudinal", completar-se-ia com a UV 11, que, mesmo marcada por grandes equipamentos, tinha uma densidade entre 11 e 30 hab/ha. Nesse caso, o que aparece no PPU como tendência longitudinal da densidade e do crescimento viraria expansão radial circular, seu reconhecimento implicaria agregar e não discriminar os espaços à sudeste da BR-116, onde estavam as classes populares. Ao tornar a tendência radial do crescimento urbano em Curitiba invisível, o PPU lança mão de novas ferramentas estratégicas para reafirmar as velhas opções seletivas das políticas urbanas.

Uma segunda mancha de densidade entre $11 \mathrm{e}$ $30 \mathrm{hab} / \mathrm{ha}$ é estabelecida (UVs 5, 6, 7, 11, 12, 13, 15 e 26) e, apesar de nitidamente circular, para os técnicos do PPU ratifica a tendência longitudinal nordeste. Objetivando confirmar a tendência longitudinal sudoeste são agrupadas, nessa segunda mancha, as UVs $29,31,33$ e 41 . Com esse desenho os urbanistas tentam convencer que a vocação da cidade é o sentido longitudinal nordeste/sudoeste e que a ocupação do Boqueirão é inorgânica. Sobre esse bairro o texto do PPU chega à seguinte conclusão: "Um apêndice que até certo ponto contraria a tendência longitudinal, mas cuja densidade é inferior a $30 \mathrm{hab} / \mathrm{ha}$, situase ao Sul e a Leste da BR-116" (PMC, 1965, p. 23; grifos do autor).

Num desenho alternativo seria plausível prolongar em forma circular (com o vértice no centro da cidade) as linhas divisórias ao sul entre as UVs 34 e 33, 33 e 41 fazendo que atravessassem e dividissem em dois pontos as UVs 35, 36 e 37 até se unirem ao limite entre as UV 22 e 38,37 e 46 , respectivamente. Com novas UVs assim

\footnotetext{
13 O tamanho grande e o recorte afunilado em direção ao centro faz que essas UVs tenham suas densidades reduzidas. Suas pequenas áreas próximas ao centro são prejudicadas pelos vastos espaços distantes do centro e que pesam negativamente no cálculo da densidade.
} 
recortadas o desenho gráfico, ao invés de segregar o Boqueirão e tomá-lo como um apêndice, estaria integrando-o à região central da cidade. $\mathrm{O}$ novo recorte manteria para a segunda faixa uma homogeneidade da densidade que tornaria evidente uma transposição do "obstáculo" BR-116 por uma parcela significativa da população - assim como a barreira da ferrovia e a forte presença de indústrias e áreas públicas nas UVs 10, 11,20,21 não evitou a forte ocupação dessa área da primeira faixa, também subavaliada pelo PPU.

É interessante observar, ainda, como o recorte retangular das UV 36 e 37 ao sul da rodovia produziu no olhar técnico uma leitura de disfunção, ao passo que o recorte idêntico das UV 14 e 26 a nordeste valorizou as suas densidades e foi tomado como uma tendência saudável para o desenvolvimento da cidade ${ }^{14}$.

Enfim, a valoração técnica do recorte gráfico deveria corresponder, e efetivamente correspondeu, a uma valorização espacial em termos de investimentos públicos planejados e a uma leitura do perfil da população em relação ao seu espaço. Realizar a leitura alternativa das densidades a partir das UV, o que fazia parte do horizonte naquele momento na proposta do engenheiro e arquiteto Onaldo Pinto de Oliveira, significaria integrar a área do Boqueirão e seus habitantes por meio da transposição da rodovia BR-116 de forma a superar o seu caráter de obstáculo.

Não se trata aqui, apenas, de revelar o quanto estava equivocada a leitura dos urbanistas a propósito de uma vocação de crescimento longitudinal nordeste-sudoeste para a cidade de Curitiba. Isso pode ser facilmente confirmado pelo Mapa 3, "Evolução da ocupação urbana" (reproduzido abaixo), que apresenta manchas radiais para cada período de ocupação, inclusive para 1966, momento em que foi elaborado o diagnóstico do PPU. O fundamental é explicar a mobilização estratégica, por parte dos urbanistas, de certos instrumentos teóricos e de intervenção, que têm efeitos precisos no jogo de forças estabelecido e na partilha desigual do espaço urbano.

14 É importante registrar que o PPU apresentava dados sobre o crescimento demográfico que revelavam a forte ocupação recente do Boqueirão, mas, neste caso, os técnicos reagruparam as UVs por Zonas e com isto minimizaram o crescimento populacional ao sul da BR-116, especialmente às margens do Rio Belém. A esse respeito ver Souza (1999).
Mapa 3 - Evolução da ocupação urbana

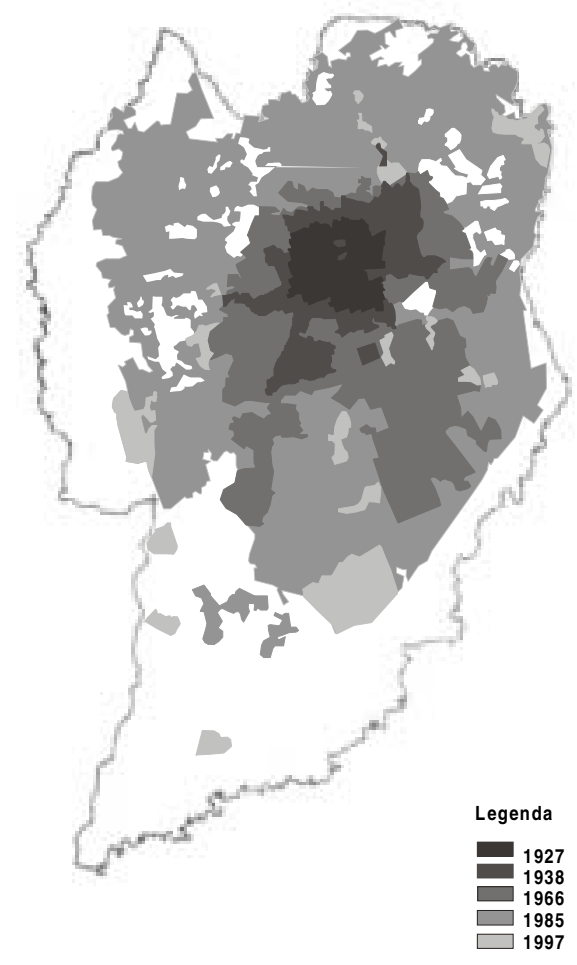

Fonte: IPPUC

É necessário sublinhar como o conceito de densidade, como substituição abstrata de experiências concretas, está ligado a práticas de classificação do espaço e da população. Ao mesmo tempo, a densidade, associada a outras "verdades", serve de critério para valorizar certos espaços e seus habitantes, o que significa desvalorizar outros, e aparece como elemento determinante do tipo de intervenção a ser empreendida pelos administradores.

O conceito de densidade adotado pelos urbanistas do PPU contrapõe-se ao de aglomeração. Densidade é entendida como ocupação ordenada do espaço, possibilitando a circulação de ar, dejetos, pessoas, e, instituindo um padrão urbano de comportamento desejável. É o oposto da aglomeração, vista como ajuntamento estagnado, que se proliferou no espaço pantanoso, de difícil drenagem, às margens das águas lentas e poluídas do Rio Belém que atravessam a morosidade da planície ao sul da BR-116. Espaço inorgânico que estaria contaminando os corpos com a preguiça e prejudicando a cidade pelo alto custo da sua reprodução. $\mathrm{Ou}$, numa leitura inversa, mas com efeitos semelhantes, os corpos preguiçosos dos "migrantes nacionais carentes" identificaram-se com este espaço 
e ocuparam-no, o que representa uma influência negativa, por ter "violentado o desenvolvimento orgânico (no sentido nordeste-sudoeste), levando a cidade a estender-se aos saltos, em trechos descontínuos" (PMC, 1965, p. 183).

O mesmo olhar tecnicamente modulado, que organizou os dados de maneira a enunciar a inviabilidade dos investimentos públicos no Boqueirão, foi usado para rebater as críticas daqueles que viam na principal avenida do bairro, a Mal. Floriano Peixoto, uma ligação natural de Curitiba com São José dos Pinhais e com o aeroporto. Wilheim conta com orgulho como encontrou a alternativa que sepultaria de vez a idéia de um eixo estrutural através do Boqueirão: "[...] as observações locais me permitiram identificar certas coisas que as pessoas locais não enxergavam. Durante muito tempo, nas reuniões com o grupo local de acompanhamento, eu falei da Avenida das Torres. Primeiro nada diziam, eu achava que não sabiam onde era e que, de repente, descobririam. De repente alguém 'ousou' perguntar: 'mas Jorge, esta Avenida das Torres de que você tanto fala, onde é?' Disse: 'é a avenida que está na frente do nariz de vocês e que vocês não enxergam! Vocês têm uma ligação direto do aeroporto, em São José dos Pinhais, até o centro de Curitiba. É área toda desapropriada, existem só as torres [torres de transmissão de eletricidade]: basta limpar e pavimentar"” (IPPUC, 1989-92, v. 5, p. 29).

Efetivamente a Avenida das Torres foi construída e com isso se evitaram maiores investimentos no Boqueirão. A via estrutural implantada nesse bairro restringiu-se à função, hierarquicamente inferior, de via coletora, como já assinalamos.

\section{FALAS ELUCIDATIVAS}

Uma comparação entre dois momentos discursivos parece ser bastante elucidativa da articulação entre o saber técnico sobre o espaço e a população com vistas à definição das prioridades da política urbana. O primeiro aparece no próprio PPU, sob uma foto aérea a legenda aponta as características do bairro do Boqueirão: trata-se de uma região "baixa, inundável e de solo inadequado para construções. A oferta de terrenos loteados levou parte da população a ocupá-la, tornando inorgânico o desenvolvimento da cidade. Recomenda-se não estimular novos loteamentos nesta região" (PMC, 1965 , p. 80; grifo do autor).
$\mathrm{O}$ segundo momento é mais recente. Numa fala retrospectiva Wilheim explica melhor o diagnóstico sobre o Boqueirão elaborado pelo PPU: "Entre nós entendíamos que tudo deveria ser feito para avançar a cidade, desenvolvê-la, a sudoeste: isto é, para não atravessar a rodovia e para não ocupar o Boqueirão. As razões para tal eram bastante sólidas. Ocupado, o Boqueirão seria destinado a uma população carente - porque o preço da terra seria sempre baixo e não haveria infra-estrutura, a não ser a um preço bastante alto [...]. Era isto, ou aquilo que propúnhamos: o desenvolvimento da cidade para Oeste e Sudoeste. Como, de fato, se fez" (IPPUC, 1989-92, v. 5, p. 32; grifo do autor).

Primeiro é preciso registrar a mudança na forma do discurso. O primeiro texto, extraído do PPU, apresenta um discurso técnico, impessoal, dirigido aos técnicos. Nele está exposta a "racionalidade" da escolha que se justifica por si só. As "necessidades" ligadas à opção em pauta não precisam fundamentos que ultrapassem o terreno técnico. Já o depoimento de Wilheim, na forma de entrevista, demonstra uma preocupação com o interlocutor e com o seu convencimento. Daí o uso da primeira pessoa do plural e o recurso à organização lógica que só oferece uma saída (racional) para quem defende o desenvolvimento. O texto técnico pôde abstrair os habitantes, não precisou adjetivar seus corpos, limitou-se à fórmula "parte da população" que por forças externas teria sido levada ao erro de ocupar um espaço inadequado. No depoimento foi preciso qualificar os corpos como "carentes", ainda que estrategicamente eles tenham sido colocados numa posição fictícia pela fala que utiliza o verbo no condicional. De todo modo, o locutor estabelece um vínculo rígido entre o meio e o tipo da população, uma afinidade mútua entre as (im)possibilidades de ambos. "Carentes", ao contrário do que possa parecer, significa nesse caso estar fora do campo das necessidades (legítimas/orgânicas) da comunidade. A forma muda do primeiro para o segundo discurso, mas o tom permaneceu o mesmo, sendo a segunda fala, pelas suas características, mais reveladora do que a primeira: aponta uma relação entre a "real" necessidade de desenvolvimento da cidade e a demanda "legítima" por investimento no espaço destinado a uma população não carente.

O depoimento de Wilheim mostra uma condicionante que atua com força no urbanismo modernista: ordenar o espaço da cidade significa também 
determinar as áreas que devem ser valorizadas monetariamente a partir de investimentos em infraestrutura e que tenham a garantia de manutenção e até de ampliação do seu valor. E o valor do espaço não está associado apenas à sua topografia, mas, fundamentalmente, aos investimentos em equipamentos urbanos. Ocorre que a intensidade e a qualidade desses investimentos pela administração pública está diretamente ligada ao tipo de população que ocupa ou ocupará um determinado espaço.

Em resumo, o valor do solo, ao longo da modernidade capitalista, tem estado associado ao seu uso, não apenas à sua finalidade, mas, principalmente, a quem se destina. Daí ser imperativo para o urbanista determinar o perfil da população que faz ou fará uso do solo e os meios para garantir a preservação do valor do espaço. Sem querer marcar uma evolução, é possível afirmar que a estratégia varia da aplicação de uma disciplina repressiva, excludente, para táticas de formação e "integração" parcial/funcional da população "carente". E para cada caso é possível investigar se a elite ocupou as melhores regiões como estratégia para captar os investimentos públicos, ou se os investimentos públicos garantiram a valorização de áreas reservadas à elite. Mas no final das contas o resultado da equação é o mesmo.

Um dos mecanismos para garantir a relação entre valor do solo e perfil população é justamente construir a tipologia dos habitantes da cidade de maneira a diferenciar aqueles que estão "aptos" a ocupar regiões valorizadas ou valorizáveis e manter esse valor, daqueles que, em razão das suas "carências", deverão passar por "processos de adaptação", os quais se concretizam como codificação de fluxos, como adequação dos corpos e/ou difusão do conformismo quanto ao lugar "natural" dos "carentes".

Da perspectiva adotada pelo PPU o valor do solo vincula-se, também, ao valor do habitante e este defini-se em relação aos seus atributos prévios e ao seu papel no processo evolutivo do desenvolvimento da cidade (que pode aparecer com o nome de realização da "vocação" da cidade para o progresso). Trata-se da prática de constituir, para cada caso, o que está dentro ou fora, o essencial e o residual, o igual e o diferente. A partir do modelo abstrato de igualdade é feita a classificação dos espaços e de seus habitantes e são planejados os procedimentos diferenciados e articulados de intervenção.
Não estando o diferente dentro da "comunidade urbana" ordenada, não tem legitimidade para opinar ou participar do processo de decisão sobre o caminho do desenvolvimento e da realização dessa mesma comunidade. A construção dos indivíduos como recipientes de necessidades a serem preenchidas limita seu potencial de sujeito do processo político. Ao ser constituído como "carente" pelos planejadores urbanos o indivíduo sofre a restrição na sua cidadania e é atingido por uma dose suplementar de discriminação e controle. O carente será objeto de políticas especiais adequadas à sua condição. As demandas dos “carentes" estão no extremo oposto daquelas dos proprietários na escala de "necessidades" elaboradas pelo urbanismo. A razão técnica que objetiva alcançar o desenvolvimento só pode se pautar pelas necessidades dos proprietários, que são as necessidades da cidade enquanto corpo saudável ${ }^{15}$.

Enfim, é a lógica do urbanismo modernista que está subjacente ao discurso de Wilheim na sua afirmação de que "razões" técnicas sólidas recomendavam que se fizesse "tudo" para não se investir numa área a ser ocupada pela população "carente". Diga-se, aliás, que a população já estava lá (ver Mapa 3, "Evolução da ocupação urbana", acima). O próprio diagnóstico do PPU apresentava esse fato, que na entrevista de Wilheim é subvalorizado com a escolha do tempo verbal de sua fala.

É preciso acrescentar que, apesar de todo o discurso valorizando uma "tendência" linear e longitudinal que discriminou o Boqueirão, o crescimento da cidade permaneceu, em grande medida, radial. Os eixos estruturais ${ }^{16}$ formaram um corredor de expansão do centro e ao mesmo tempo geraram uma valorização e preservação dos círculos concêntricos historicamente reservados à elite. Em resumo, foi gerado um suplemento de valor sobre o que já era valorizado, e esse é, sem dúvida, o elemento central na elucidação do discurso contido no PPU e das intervenções urbanas articuladas a ele. A sobrevalorização de

\footnotetext{
15 No caso de Curitiba é nítido o esforço dos urbanistas em estabelecer um padrão de "participação" dos citadinos no planejamento da cidade restrito ao reconhecimento e aprovação do "saber técnico" acima de qualquer discussão e interferência.

16 O desenho original dos eixos estruturais pode ser observado no Mapa 1, "Proposta de esquema viário - PPU" (reproduzido no início deste artigo).
} 
espaços já valorizados, a partir da construção de uma tendência linear nordeste-sudoeste como vocacional e racional, pode ser percebido com a sobreposição do Mapa 4, "Valores imobiliários de terrenos - PPU" (1965, reproduzido abaixo) com o Mapa 1, "Proposta de esquema viário - PPU" (reproduzido no início) que apresenta o traçado dos eixos estruturais.

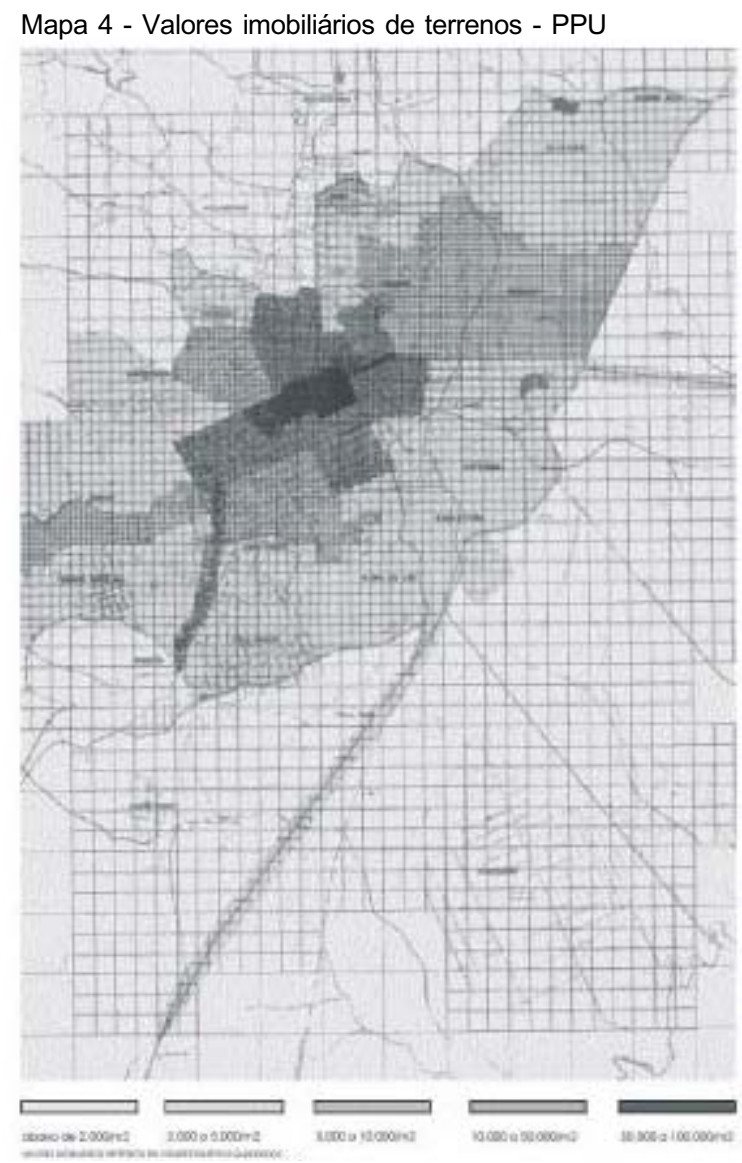

A observação dos mapas confirma que os miolos espaciais localizados entre os eixos e as demais avenidas perpendiculares e circulares foram valorizados assim como suas adjacências. Significa que a ordem urbana precedente foi não apenas respeitada, mas também expandida e sobrevalorizada com o PPU. O desenho da nova expansão, é importante frisar, continuou radial, tanto no que se refere aos valores imobiliários quanto no que diz respeito ao avanço da ocupação urbana, com o detalhe de que o caráter radial do crescimento dos valores imobiliários permaneceu, por muito tempo, restrito às proximidades dos eixos estruturais. Esse detalhe confirma o sucesso estratégico do PPU e pode ser conferido pelo Mapa 5, "Custo da terra. Valores imobiliários, 1985", reproduzido abaixo.

Mapa 5 - Custo da terra. Valores imobiliários, 1985

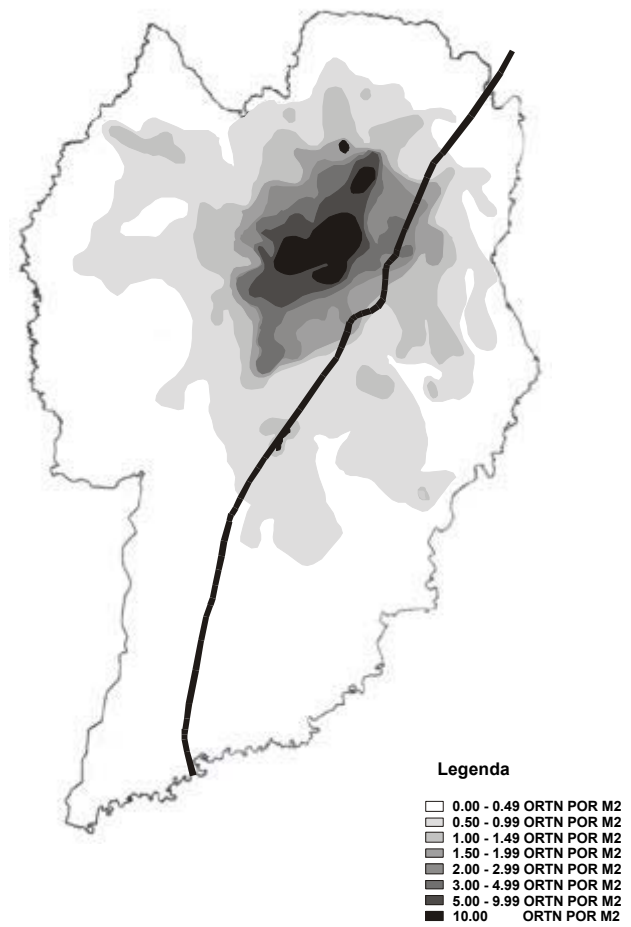

Fonte: IPPUC

Para o PPU a estrutura viária teria facilitado a ocupação indesejável de bairros como o Boqueirão. O Plano propõe corrigir essa situação justamente associando o novo sistema viário à regulação do uso do solo e ao sistema de transporte, impedindo assim as "ocupações inorgânicas" nas proximidades dos eixos que passaram a valorizar os espaços urbanos centrais e longitudinais à rodovia BR-116. Tal procedimento formou um estoque de investimentos e de expansão "saudável" para a cidade ao limitar o desenvolvimento das áreas ocupadas por habitantes de baixa renda relativamente próximas ao centro (ver foto, reproduzida acima). Nesse sentido, o êxito do sistema de transporte, celebrado com vigor pela administração e pela mídia, traduzse pela eficiência em viabilizar um distanciamento cada vez maior das classes populares, porém sem as isolar completamente.

Ao contrário de barreira, a BR-116, vista do lado de dentro, formaria uma proteção lateral para a expansão longitudinal "saudável" do corpo urbano. Construir ou expandir uma densidade ordenada seria colocar uma população num espaço saudável porque planejado. O problema das grandes cidades, diagnosticado pelos urbanistas curitibanos, é 
que primeiro as pessoas se estabelecem nos espaços de maneira desordenada e somente depois os governos tentam levar até elas a racionalidade do planejamento. Como o crescimento das cidades, sem o devido monitoramento técnico, segue uma tendência radial-perimetral, ou seja, dá-se uma expansão desordenada para todos os lados, as administrações têm dificuldade de reordenar as ocupações espontâneas e irregulares. Dito de outro modo, formado o cinturão de pobreza e desordem em volta do centro organizado da cidade, segundo os urbanistas do PPU, esta tem grandes dificuldades para expandir-se porque a barreira à circulação e aos investimentos está instalada. A concentração das atividades no centro das cidades, especialmente a função trabalho, contribuiria para uma ocupação indevida deste espaço e de suas proximidades. A multiplicidade de atividades e grupos sociais no mesmo espaço geraria o caos. O que o planejamento fez, no caso de Curitiba, foi ao mesmo tempo preservar o centro e garantir a expansão da sua ordem. O plano possibilitou ao centro um crescimento regulado na justa medida que abriu com os eixos estruturais o caminho para que sua lógica se estendesse com segurança. Não que o crescimento da cidade tenha seguido o traçado linear. A Curitiba pós-PPU cresceu a partir do centro de maneira radial, mas sem o risco de bloqueio pela ocupação do espaço por grupos populares. Daí o real sentido da segurança e a insistência na linearidade. A hierarquia entre funções e agrupamentos foi garantida pela nova configuração urbana. Os eixos estruturais, combinados com as grandes avenidas e com a própria BR-116, cumpriram, então, um papel estratégico: proteção, expansão e valorização dos espaços nobres, na justa medida da contenção dos pobres nos seus lugares distantes.

\section{CONCLUSÃO}

Os urbanistas que elaboraram o PPU, e que depois comandaram a reforma urbana da cidade, mobilizaram as categorias de densidade, dispersão, vocação urbana e empreenderam a classificação do espaço e da população a partir da concepção de necessidade como atributo natural tanto do corpo urbano como do corpo humano, ambos definidos abstratamente em relação ao equilíbrio e ao desenvolvimento.

O PPU, a partir da perspectiva do urbanismo modernista, construiu o habitante urbano de Curitiba como objeto das intervenções planejadas. Diante do seu objeto os agentes do planejamento urbano foram fortalecidos na mesma proporção em que a população encontrou bloqueios à sua participação política num espaço público plural. Esse limite foi experimentado principalmente pelas classes populares representadas como "carentes" e habitantes de um "apêndice inorgânico" da cidade saudável.

O efeito mais visível da insistência "técnica" em escolher o sentido nordeste-sudoeste como prioritário para instalação dos eixos estruturais, foi garantir um valor suplementar aos espaços centrais já valorizados e gerar um estoque para sua expansão. Aliás, essa é a lógica capaz de elucidar os investimentos teóricos e práticos na definição do lugar do eixo estrutural. O eixo, opção prioritária para os investimentos públicos e privados, foi instalado sobre os espaços economicamente mais valorizados da cidade, onde habitava a população considerada organicamente integrada ao desenvolvimento urbano. O quadro representativo da cidade e sua "vocação" só pôde ser completado com a representação da região ao sul da BR116, especialmente o bairro do Boqueirão, como contraponto negativo do espaço positivo, ou seja, como "apêndice" inorgânico da cidade orgânica. Porque não dizer, um apêndice inflamado que, aos olhos dos técnicos, precisava ser separado do corpo urbano saudável.

O recente plano estratégico dos urbanistas curitibanos prevê a transformação da BR-116, de antiga fronteira da cidade orgânica, em novo eixo estrutural. Trata-se de uma realidade que ainda precisa ser investigada. As primeiras impressões permitem afastar a hipótese de uma integração de espaços e populações excluídas no passado pelo PPU. Primeiro, porque os habitantes do Boqueirão têm hoje outro perfil. As fronteiras da cidade deslocaram-se e hoje coincidem, em grande parte, com as linhas divisórias do município. Uma pista interessante para investigação dessa realidade está em associar a nova proposta à necessidade de incessantes empreendimentos para manter a cidade como núcleo atrativo de investimentos e modelo de adequação à rede mundial globalizada. Não se trata portanto da integração das classes populares, hoje habitantes dos municípios vizinhos, como faz crer o discurso do planejamento. A elas restará, como no caso do primeiro eixo estrutural projetado no PPU, admirar os edifícios pósmodernos da janela do transporte coletivo. Como no passado, o futuro eixo da BR-116, com uma 
nova escala de transporte de massa, será a garantia do distanciamento "seguro" dos "carentes" e de um novo estoque de espaços a serem ocupados pela população organicamente integrada.

Recebido para publicação em 30 de junho de 2001.

Nelson Rosário de Souza (nrdesouza@uol.com.br) é Doutor em Sociologia pela Universidade de São Paulo (USP) e Professor de Ciência Política na Universidade Federal do Paraná (UFPR).

\section{REFERÊNCIAS BIBLIOGRÁFICAS}

ARANTES, O. 1998. Urbanismo em fim de linha e outros estudos sobre o colapso da modernização arquitetônica. São Paulo : Edusp.

. 2000. Uma estratégia fatal : a cultura nas novas gestões urbanas. In : (org.). $A$ cidade do pensamento único : desmanchando consensos. Petrópolis : Vozes.

BAUDRILLARD, J. 1969. La genèse idéologique des besoins. Cahiers Internationaux de Sociologie, Paris, ano XLVI, p. 45-68, jul.-dez.

DREYFUS, J. 1976. La ville disciplinaire : essai sur l'urbanisme. Paris : Galilée.

DUPUY, G. 1978. Le rôle politique et idéologique de la technique dans l'aménagement des villes : de l'assainissement à la planification des transports urbains. Colloque de Recherche Urbaine "Aménagement urbain et mouvements sociaux", Paris, Centre de recherche d'urbanisme, avril.

FCC. 1995. Boqueirão : o bairro na história da cidade. Boletim informativo da Casa Romário Martins, Curitiba, Fundação Cultural de Curitiba, v. 22, n. 106, ago.

FOUCAULT, M. 1979. Microfisica do poder. Rio de Janeiro : Graal.

. 1990. Omnes et singulatim : por uma crítica da razão política. Novos Estudos CEBRAP, São Paulo, n. 26, p. 77-99, mar.

FOURQUET, F. (org.). 1973. Genealogie $d u$ capital. v. 1 : Les équipements du pouvoir : villes, territoires et équipements collectifs. Paris : Recherches.

GUATTARI, F. 1985. Espaço e poder : a criação de territórios na cidade. Espaço e debates, São Paulo, ano V, n. 16, p. 109 - 120, ou.-dez.

HABERMAS, J. 1987. Arquitetura moderna e pós-moderna. Novos Estudos CEBRAP, São
Paulo, n. 18, p. 115-124, set.

HOLSTON, J. 1993. Cidade modernista : uma crítica de Brasília e sua utopia. São Paulo : Cia. das Letras.

IBGE. 1950-1991. Censo demográfico do Paraná. Rio de Janeiro: Instituto Brasileiro de Geografia e Estatística.

IPPUC. 1989-92. Memória da Curitiba urbana. Depoimentos. 8 volumes. Curitiba: Instituto de Pesquisas e Planejamento Urbano de Curitiba.

KLEINKE, M. L., WENECK, D. Z., MOURA, R. \& DESCHAMP, M. V. 2000. Movimento migratório na região metropolitana de Curitiba : 1986-1991 e 1991-1996. Metrópolis em revista, Curitiba, ano 2, n.1, p. 21-29, dez.

PMC. 1965. Plano preliminar de urbanismo de Curitiba. Curitiba: Prefeitura Municipal de Curitiba/Serete \& Wilheim Associados.

1966. Mensagem do Plano Diretor. Anteprojeto de Lei. Maio.

SÁNCHEZ, F. E. 1997. Cidade espetáculo : política, planejamento e city marketing. Curitiba : Palavra.

2001. A reinvenção das cidades na virada do século : agentes, estratégias e escalas de ação política. Revista de Sociologia e Política, Curitiba, n. 16, p. 33-51, jun.

SENNETT, R. 1997. Carne e pedra : o corpo e a cidade na civilização ocidental. Rio de Janeiro : Record.

TOPALOV, C. 1996. Da questão social aos problemas urbanos : os reformadores e a população das metrópoles em princípios do século XX. In : RIBEIRO, L. C. Q. \& PECHMAN, R. (orgs.). Cidade, povo, nação. Rio de Janeiro : Civilização Brasileira. 
ULTRAMARI, C. \& MOURA, R. (orgs.). $1994 . \quad$ Metrópole : Grande Curitiba : Teoria e prática. Curitiba : IPARDES.

\section{OUTRAS FONTES}

CURITIBA. 1966. Plano Diretor. Lei no 2 828/ 66.
Os bairros deveriam ser ouvidos: Associações protestam contra a Carta da Favela na Prefeitura. Correio de notícias, Curitiba, 15.maio.1980, p. 7. 